\title{
El todo es mayor a la suma de sus partes: la teoría politica de Suárez y la tradición contractualista
}

The whole is greater than the sum of its parts: Suarez's political theory and the social contract tradition

Felipe Schwember Augier

Universidad Adolfo Ibáñez felipe.schwember@uai.cl

Daniel Loewe Henny

Universidad Adolfo Ibáñez daniel.loewe@uai.cl

DOI: https://doi.org/10.15366/bp2021.26.008

Bajo Palabra. II Época. No26. Pgs: 161-178 
Recibido: 10-09-2020

Aceptado: 24-09-2020

Resumen

El presente trabajo procura situar la teoría política de Francisco Suárez en la tradición contractualista y, con ello, examinar la relación general entre contractualismo y iusnaturalismo. Se sostendrá que Suárez es contractualista en un sentido calificado del término y que, en ese peculiar sentido, no existe incompatibilidad entre contractualismo y ley natural sino, por el contrario, complementariedad. Se examina finalmente su tesis del carácter emergente de la potestad política para, a partir de ella, sugerir alguna diferencia con las teorías políticas modernas.

Palabras clave: Contractualismo, Francisco Suárez, propiedad, autoridad, derecho de gentes.

\section{Abstract}

The present work attempts to place the political theory of Francisco Suarez in the social contract tradition and by so doing examine the general relationship between contractualism and natural law. It will argue that Suarez is a social contract theorist in a qualified sense of the term and in using that sense the work will show that there is complementarity rather than incompatibility between contractualism and natural law. Finally, it examines Suarez's thesis on the emergent character of political power to suggest some points of difference with modern political theory.

Keywords: Social contract, Francisco Suarez, property, authority, ius gentium. 


\section{Introducción}

AunQue los especialistas Se ENCUeNTren CONTESTes en que la teoría política salmantina sirve de gozne entre el pensamiento político medieval y el pensamiento político moderno, no están de acuerdo en la naturaleza y alcance de esa mediación. Una de las aristas de ese impreciso consenso es el problema de si los teólogos salmantinos pueden ser o no calificados de "contractualistas" y, en caso afirmativo, de en qué medida podrían serlo ${ }^{1}$.

Una de las dificultades con que tropieza la dilucidación de esa pregunta es, obviamente, la equivocidad del término "contractualismo": en el peor de los casos habría tantos contractualismos como filósofos contractualistas y, en el mejor, tres familias de teorías contractualistas, que se corresponderían grosso modo con los modelos desarrollados por los contractualistas clásicos: Hobbes, Locke y Rousseau. Esta equivocidad no sólo dificulta la investigación, sino que, peor aún, arriesga volverla trivial o estéril, pues siempre podrá afirmarse que tal o cual teólogo salmantino podrá o no ser contractualista dependiendo de la definición de contractualismo que se adopte.

En el presente trabajo intentaremos lidiar con estas dificultades con el objeto de determinar el sentido en que Francisco Suárez puede ser considerado un filósofo contractualista, si es que acaso se lo puede considerar como tal en absoluto. Para ello elaboraremos primero una taxonomía general de las teorías contractualistas. La idea es arribar a una caracterización general del contractualismo y establecer un significado primario para el concepto de "contractualismo". Esta primera indagación nos permitirá desbrozar parte de las dificultades que rodean la relación entre el contractualismo y las teorías políticas de los autores salmantinos en general y de Francisco Suárez en particular.

\footnotetext{
${ }^{1}$ Cf. por ejemplo, Letelier Widow, G., "La noción de "estado de naturaleza" en el pensamiento político español del siglo XVI", Ideas y valores 67, no. 167 (2018): 199-222, Schwartz Porzecanski, D. "Francisco Suárez y la tradición del contrato social." Contrastes: revista internacional de filosofia, no. 10 (2005): 119-38 o Tellkamp, J. A., "Francisco de Vitoria and Luis de Molina on the Origin of Political Power" en Right and Nature in the First and Second Scholasticism. Derecho y naturaleza en la primera y segunda escolástica, Alfredo Santiago Culleton y Roberto Hofmeister Pich (eds.). Bélgica: Brepols, 2014, pp. 231-47.
} 
En seguida - y descartada la aplicabilidad del significado primario de "contractualista" a Suárez- pasaremos a revistar otros conceptos derivados de contractualismo. Sostendremos que algunos de estos conceptos secundarios son, en efecto, aplicables a Suárez, quien por lo mismo puede ser considerado como contractualista en un sentido cualificado del término.

Luego llamaremos la atención sobre algunas de las diferencias entre el contractualismo de Suárez y el de Locke. Más exactamente, la diferencia que existe entre concebir el poder político como una potestad emergente de la asociación política (como hace Suárez) y concebirlo como reducible a los derechos naturales que tienen los individuos que se congregan en una comunidad política. Sugeriremos que aquí se encuentra una diferencia crucial, no ya solo con Locke, sino con todas las demás teorías contractualistas en general.

\section{Taxonomías del contractualismo y sus significados primarios}

LA PRIMERA DIFICULTAD con que tropieza quien quiera ofrecer una definición de contractualismo es la de dar con un mínimo común denominador de las diferentes teorías agrupadas bajo la categoría de "contractualistas". Si se repasan tales teorías, nos encontraremos con autores que sostienen tesis muy diferentes acerca de la naturaleza de las obligaciones políticas o del papel que el consentimiento juega en ellas. Así, por ejemplo, encontraremos autores para los que las obligaciones políticas surgen en efecto de una promesa, mientras que otros sostienen que el recurso al contrato no debe ser tomado de un modo literal, como el de quien mienta con él un hecho histórico, sino tan solo como un mecanismo de representación por medio del cual arribar a los principios de justicia que habrán de gobernar la vida en común. Del mismo modo, se encontrarán autores que entienden que el contrato social instaura por primera vez la distinción entre la justicia y la injusticia, mientras que otros sostienen que lo mío y lo tuyo son anteriores a cualquier contrato y que el mismo no hace en realidad otra cosa que refrendar y asegurar lo suyo de cada uno.

Sin embargo, esta desalentadora variedad puede ser reducida a partir de ciertas clasificaciones. Para ello, propondremos los siguientes criterios de clasificación: el primero, referido a la función que desempeńa el contrato social de cara al contenido de los vínculos normativos; el segundo, a partir de la motivación que en cada caso se presupone en los agentes; el tercero referido a la materia del contrato; y el cuarto, referido al estatus ontológico del contrato. Esos criterios se dividen, a su vez, en las siguientes clasificaciones: 


\section{a) Contractualismo fuerte y contractualismo débil}

Diremos que una teoría adhiere al contractualismo fuerte cuando en ella se sostiene que todos los vínculos normativos son resultado de un acuerdo, de modo que antes del contrato no existen propiamente obligaciones, de ningún tipo. Dicho de otro modo, la situación precontractual es una situación de total vacio normativo. Este vacío normativo podría quedar ilustrado por el pasaje del Leviatán en que Hobbes afirma que "las nociones de lo moral y lo inmoral, de lo justo y de lo injusto no tienen allí [en el estado de naturaleza] cabida. Donde no hay un poder común no hay ley; y donde no hay ley, no hay injusticia [...] En una situación así, no hay tampoco propiedad, ni dominio, ni un mío distinto de un tuyo" ${ }^{2}$.

Por contraposición a este tipo de contractualismo, puede afirmarse que una teoría contractualista es débil cuando las partes contratantes están constreñidas por ciertas restricciones precontractuales cuya observancia es condición de la validez del acuerdo. Un ejemplo de este tipo de contractualismo se encuentra en la teoría política de Locke, para quien el estado de naturaleza no es un estado de licencia. Hay en él, por el contrario, "una ley de naturaleza que lo gobierna y que obliga a todos". En virtud de esa ley todos los hombres son "iguales e independientes" y "ninguno debe dañar a otro en lo que atañe a su vida, salud, libertad o posesiones" 3 .

En consecuencia, para Locke el estado de naturaleza tiene ciertas reglas (la ley natural) y derechos individuales, que informan tanto la negociación como el acuerdo final ${ }^{4}$. De ahí que, conforme a este tipo de contractualismo, no sean admisibles ciertas clases de acuerdo. Eso es particularmente claro también en el caso de Rousseau —otro exponente del contractualismo débil - : los pactos que consagran la servidumbre, la desigualdad y que, en fin, consagran la alienación de quienes los suscriben son nulos y de ningún valor ${ }^{5}$.

\section{b) Contractualismo egoísta, individualista y universalista}

Esta clasificación parte de la motivación que se atribuye a los agentes que participan de la negociación. A partir de ella se puede identificar un contractualismo

\footnotetext{
${ }^{2}$ Hobbes, T., Leviatán o la materia, forma y poder de una República eclesiástica y civil, Buenos Aires, Fondo de Cultura Económica. 1992, p. 104

3 Locke, J., Segundo tratado sobre el gobierno civil: un ensayo acerca del verdadero origen, alcance y fin del gobierno civil, Madrid, Alianza Editorial, 2000, $\$ 6$

${ }^{4}$ Ibid., \$\$6-7

5 Rousseau, J.-J., Del contrato social. Discursos, Madrid, Alianza Editorial, 1998, pp. 302 y ss.
} 
egoista, es decir, aquel que asume - bien por pesimismo antropológico, bien por razones metódicas - que los agentes no tienen otra motivación que la consecución de alguna ventaja. Dicho de otro modo, la racionalidad que se atribuye a los agentes es puramente instrumental, de modo que los bienes que se buscan son — dicho en lenguaje escolástico- bienes útiles. La república de demonios a que se refiere Kant en Paz perpetua podría ser un buen ejemplo de este tipo de motivación ${ }^{6}$.

En el caso del contractualismo individualista, en cambio, la consecución del propio provecho está limitada por ciertas reglas, que a su vez no están fundadas en la lógica puramente instrumental de la propia ventaja. La ley natural en las teorías del derecho natural de inspiración lockeana son un ejemplo de este tipo de contractualismo.

El contractualismo universalista, por su parte, exige que los agentes juzguen imparcialmente todos los intereses, incluidos los suyos propios. Esa motivación desinteresada permite "universalizar" los intereses y, con ello, permite decir —en clave escolástica, otra vez - que el bien que persiguen es un bien honesto (la justicia) y no puramente útil.

\section{c) Contractualismo realista, libertario e igualitario}

Se puede establecer otra clasificación según el modo en que las teorías contractualistas tratan la materia del contrato, es decir, la determinación de lo suyo de cada uno. Aquí son posibles varias alternativas. La primera - que llamaremos contractualismo realista - consiste en sostener que el contrato determina íntegramente lo suyo de cada uno. Antes del contrato, en consecuencia, no existen reglas de adquisición y nadie es dueño de nada, ni por lo que toca a los bienes externos ni por lo que toca a la propia persona. Por eso, la consigna de este contractualismo podría quedar resumida en el famoso dictum hobbesiano de que en el estado de naturaleza (i.e., el estado precontractual) cada individuo tiene derecho a hacer cualquier cosa, incluso en el cuerpo de los demás ${ }^{7}$. Conforme a esta clase de contractualismo, sería perfectamente legítimo que la distribución resultante reflejara las diferencias de poder o cualesquiera otras ventajas precontractuales. Por esa razón podría ser el caso que incluso la distribución de lo "suyo interno de cada uno" fuera dispareja. Como afirma Buchanan: "[l]a delineación de los derechos de propiedad es, de hecho, el instrumento o el medio por el cual se define inicialmente a una "persona»"

\footnotetext{
${ }^{6}$ Kant, I., Gesammelte Schriften (Akademie-Ausgabe), Walter de Gruyter Berlin, 1900, VIII, p. 366. 7.

7 Hobbes, T., Leviatán, op. cit., p. 107.

${ }^{8}$ Buchanan, J.M., Los límites de la libertad. Entre la anarquia y el Leviatán, Madrid, Katz Editores, 2009, p. 28.
} 
En las antípodas del contractualismo realista se puede encontrar lo que llamaremos contractualismo libertario. Conforme al mismo, tanto lo suyo interno de cada uno, como las reglas para la adquisición de lo mío y lo tuyo externo son determinadas antes del contrato. Por esta razón, el contrato se limita a refrendar tales reglas, así como las adquisiciones realizadas en conformidad con ellas. Eventualmente, el contrato puede servir para determinar lo que las reglas precontractuales de adquisición hubieran dejado indeterminado. El ejemplo paradigmático de este tipo de contractualismo es Locke. Se podrían citar múltiples pasajes del Segundo tratado en los que Locke afirma que la finalidad del gobierno es proteger la propiedad de los ciudadanos. Esos pasajes se podrían complementar con aquel pasaje en que Locke explica las reglas precontractuales de adquisición de la propiedad y, sobre todo, con aquel en que afirma que "cada hombre es propietario de su propia persona, sobre la cual nadie, salvo él mismo, tiene ningún derecho" 9 .

Llamaremos, por último, contractualismo igualitario a aquel que manda realizar la división según la regla distributiva que ordena preservar la igualdad natural de los contratantes. Aquí todo es puesto en común para que luego pueda ser dividido de modo más o menos equitativo. Rousseau, nuevamente, sirve de ejemplo para ilustrar el modus operandi de este tipo de contractualismo. Por ejemplo, por lo que respecta a lo suyo interno de cada uno, el contrato social se traduce en que "cada uno de nosotros pone en común su persona y todo su poder bajo la suprema dirección de la voluntad general; y nosotros recibimos corporativamente a cada miembro como parte indivisible del todo" 10 .

Por lo que concierne a la distribución de poder y riqueza, el resultado del contrato ha de ser tal que nadie ejerza aquel "sino en virtud del rango y las leyes" y que nadie tenga tanta de ésta como "para poder comprar a otro" ni tan poca como "para ser constreñido a venderse" ${ }^{11}$.

\section{d) Contractualismo efectivo y contractualismo hipotético}

El tercer criterio tiene que ver con la historicidad del pacto. Este criterio surge de la pregunta de si acaso el contrato social necesita ser un hecho histórico (contractualismo efectivo) o basta concebirlo como una ficción metódica (contractualismo hipotético). En el primer caso, no es necesario que haya tenido lugar de modo for-

\footnotetext{
${ }_{9}$ Locke, J., Segundo tratado..., op. cit., $\$ 27$.

${ }_{10}$ Rousseau, J.-J., Del contrato social, op. cit., p. 39.

11 Ibíd., p. 76.
} 
mal. Basta con que se aduzca que la realidad del pacto consiste en el consentimiento tácito que se da a una autoridad o sistema de reglas, tal como hacen Sócrates en el Critón o Locke en el Segundo tratado. Pero, ya sea que se trate de un consentimiento expreso o tácito, el punto decisivo para los defensores de lo que aquí hemos llamado contractualismo efectivo es que los ciudadanos, todos, en efecto hayan consentido.

Sin embargo, las dificultades que conlleva insistir en la historicidad o exigir la unanimidad del acuerdo, han llevado a varios autores, y particularmente a Kant, a sostener que "en modo alguno es preciso suponer" que el contrato social es un hecho; que bien se lo puede concebir como "una mera idea de la razón que tiene, sin embargo, su indudable realidad (práctica), a saber, la de obligar a todo legislador a que dicte sus normas como si éstas pudieran haber emanado de la voluntad unida de todo un pueblo" ${ }^{12}$.

Llegado el punto en que se prescinde del consentimiento efectivo de los gobernados y en que el contrato es tenido como un "mecanismo de representación" ${ }^{13}$, resulta inevitable preguntarse por el papel que el consentimiento desempeña en la teoría. En tal caso, el contrato puede tener valor por su función heurística, pero no porque de hecho se haya suscrito un acuerdo. Como afirma Dworkin "[u]n contrato hipotético no es simplemente una forma desvaída de un contrato real; lisa y llanamente, no es un contrato" ${ }^{14}$.

\section{El contractualismo primario y el derecho natural}

Diremos QUe, De todas las Clases de contractualismos seÑalados, el contractualismo fuerte, egoista, realista y efectivo constituye el significado primario del concepto "contractualismo". La razón es que ninguna otra variante posible del contractualismo atribuye una función más amplia y de mayor alcance al contrato. De hecho, ningún otro contractualismo posible es capaz de elaborar toda la teoría de la justicia únicamente a partir del contrato y un presupuesto psicológico tan parco como el propio interés. A los restantes, no primarios, los llamaremos contractualismos derivados.

Uno podría preguntarse ahora qué autores adscriben o recurren a este tipo de contractualismo. Tal vez el caso paradigmático sea Hobbes y, en su estela, Buchanan o Stemmer, aun cuando en ellos el contrato ya sea claramente una herramienta

\footnotetext{
12 Kant, I., Ak. VIII, p. 297.

13 Rawls, J., La justicia como equidad. Una reformulación, Barcelona, Paidós, 2002, p. 41.

${ }_{14}$ Dworkin, R., Los derechos en serio, Barcelona: Editorial Ariel, 1984, p. 235.
} 
heurística y no un contrato efectivo. Sin embargo, eso no tiene mayor importancia aquí. Lo que importa subrayar ahora es que, independientemente de quiénes hayan adscrito al contractualismo primario, es claro que Suárez no se encuentra entre ellos. Por el contrario, Suárez no cree ni pretende que por el contrato (la sola voluntad de los hombres, digamos) se constituyan todos los vínculos normativos, ni por lo que se refiere a su validez, ni por lo que se refiere a su contenido. Y esto es cierto, no sólo respecto de las obligaciones morales, sino también de las jurídicas. Por de pronto, todas las obligaciones de derecho natural lo son - dicho en términos suarecianosen razón de su bondad intrínseca. De hecho, a propósito de la pregunta de si acaso la ley natural consiste en la recta razón natural, Suárez afirma que "las naturalezas intrínsecas y las esencias de los actos morales son inmutables, y no dependen de una causa o de una voluntad extrínseca más que las demás esencias de las cosas que de suyo no implican contradicción" ${ }^{15}$.

Asimismo, uno de los criterios que emplea para identificar la ley natural y distinguirla de otros tipos de leyes es que estas últimas "hacen malo lo que prohíben y necesario u honesto lo que mandan" mientras que aquella "supone en el acto u objeto honestidad para mandarla y fealdad para prohibirla; por eso suele decirse que esta ley prohíbe algo porque es malo y manda algo porque es bueno" ${ }^{16}$.

La bondad o maldad intrínseca de tales actos, por último, vuelve no sólo superfluos sino, más aún, inadmisibles los eventuales acuerdos encaminados a modificar de algún modo las leyes que prescriben o prohíben tales actos. Por eso Suárez afirma que "otras leyes naturales hay que obligan inmediatamente en sus materias propias independientemente de todo consentimiento previo de la voluntad del hombre" ${ }^{17}$.

Pero, además, tampoco es el caso que para Suárez la rectitud del contrato —allí donde tiene cabida - se encuentre únicamente en la utilidad de aquellos que lo celebran. Si se estima que el contrato social cae total o parcialmente bajo lo que Suárez llama ley civil, entonces no debe perderse de vista que esta última "atiende a la utilidad temporal honesta de la república humana" ${ }^{18}$. Eso, presumiblemente, coloca a los agentes que lo suscriben en una categoría semejante a lo que más arriba llamábamos contractualismo individualista, no en la categoría del contractualismo egoista. Y si se considera, en cambio, que las materias sobre las que versa el contrato corresponde a la del derecho de gentes, entonces con mayor razón han de caer en alguna categoría diferente del contractualismo egoísta. Considerando, de hecho, la

\footnotetext{
15 Suárez, F., Las Leyes, Madrid ,Instituto de Estudios Políticos, 1967, II, 5, 2

16 Ibid., II, 7, 1.

17 Ibid., II, 14, 6.

${ }^{18}$ Ibid., III, 11, 6.
} 
proximidad del derecho de gentes al derecho natural ${ }^{19}$, la motivación de los agentes en este último caso bien podría ser la del contractualismo universalista. Todo esto nos lleva a otro problema, más general, acerca de la relación entre derecho natural y contractualismo. Las teorías iusnaturalistas pueden combinarse con diferentes modos de contractualismo secundarios y, en tales casos, las materias sobre las que versa este último caen, o bien sobre lo que los autores escolásticos llaman derecho de gentes, o bien sobre lo que llaman derecho humano. Por consiguiente, el contenido del acuerdo en los contractualismos secundarios se obtiene, o bien por deducción a partir de los principios, o bien de una determinación de los principios de la ley natural. Piénsese, por ejemplo, en el caso de la división de los bienes, que es introducida por derecho de gentes. Dada, por su parte, la proximidad antedicha entre el derecho de gentes y el derecho natural, eso significa que la propiedad privada:

1) Ha sido dada concesivamente por la ley natural (pues la comunidad originaria de bienes es establecida sólo negativamente por ella) ${ }^{20}$.

2) No tiene — por lo que toca a su rectitud — la misma necesidad y evidencia que otras instituciones. El derecho de gentes trata de materias "no intrínsecamente necesarias" 21.

3) Podría no haber sido nunca introducida. Sin embargo, normalmente es mejor que así haya sido. Hay argumentos de derecho natural en favor de su introducción.

4) Es de derecho natural, como ocurre con todas las obligaciones que manda cumplir la segunda tabla ${ }^{22}$.

5) Puede haber sido introducida por propagación o imitación mutua, "sin necesidad de una reunión o convenio especial de los pueblos en un momento dado". Se propagó, añade Suárez, "de manera natural" 23.

Pues bien, así las cosas, la propiedad privada ¿es de derecho natural, de derecho de gentes o de derecho humano? ¿ $\mathrm{O}$ en parte de todos ellos, pero de diferentes modos y bajo distintos respectos? Su fundamento se halla en el derecho natural (o

\footnotetext{
19 Ibid., II, 20, 1.

20 “[E]s cosa cierta que [la ley natural] concede muchos bienes -digámoslo así- permisivamente más bien que preceptivamente respecto de los particulares a quienes se hace tal concesión. Así -por ejemplo- concedió a los hombres el reparto de la propiedad de las cosas, ya que el repartir las cosas y adquirir propiedad particular es de derecho natural; ahora bien, no lo es por precepto, porque podían los hombres no hacer reparto ni adquirir propiedad particular; luego lo es por permisión”. Ibid., I, 16, 7.

${ }^{21}$ Ibid., II, 17, 7.

22 Ibid., II, XV, 9 y 10.

23 Ibid., II, 20, 1.
} 
deriva de él), aunque su instauración es por convención, aun cuando se trate de una convención tácita. Pero la instauración de un régimen de propiedad privada requiere muchas determinaciones de derecho humano y por esa razón no es posible decir que la propiedad sea puramente convencional o puramente de derecho natural ${ }^{24}$.

Como el ejemplo de la propiedad pone de manifiesto, en el contractualismo derivado la contraposición entre ley natural (o derecho natural) y contrato es bastante artificial, pues los mismos acuerdos (ya sean expresos o tácitos) son informados por ciertos principios precontractuales. Esto es particularmente claro en el caso de aquellos cuyo contenido deriva por deducción de los principios naturales. En tales casos es más apropiado decir que se ha acordado en algo porque es justo (o bueno) que, a la inversa, decir que es justo porque se lo ha acordado. Los acuerdos que derivan por conclusión simplemente refrendan tales principios o los hacen operativos.

En aquellos otros cuya materia deriva por determinación de la ley natural, el asunto no es tan diferente. En tales casos, el contenido del acuerdo es arbitrario, pero no, sin embargo, irracional. Es arbitrario en la medida en que versa sobre materias que pueden definirse indistintamente de un modo u otro, pero no en el sentido de que el ejercicio mismo de adoptar acuerdos acerca de tales cosas sea irracional. La posibilidad de que ciertas cosas sean buenas porque son acordadas (o mandadas, según el caso) se explica, en último término, por su inclusión dentro de un marco normativo más amplio — la ley natural— que da sentido a acuerdos y decisiones de ese tipo.

Pero, así como el contrato halla las condiciones de su obligatoriedad en el marco normativo de la ley natural, la ley natural requiere de acuerdos de este tipo que, como decíamos, hagan los principios operativos. Por tal motivo, en lo que aquí hemos llamado contractualismo derivado, la relación entre los principios precontractuales (naturales o a priori o de otro tipo) y el contrato es de complementariedad y no de oposición ${ }^{25}$. Esta relación de complementariedad es previsible, por otra parte, una vez admitida la igualdad natural de los hombres y rechazada, por consiguiente, la existencia de seńores naturales o la designación directa de los gobernantes por parte de Dios.

\footnotetext{
${ }^{24}$ Para la teoría de Suárez de la propiedad, cf., por ejemplo, Lecón, M., “¿Es Francisco Suárez un defensor de la propiedad comunitaria? Una revisión de la interpretación de Eduardo Nicol”. Diánoia, 2017.62 (78): p. 183-201 o Hernández-Fradejas, F., "Derecho de propiedad privada y fiscalidad en Francisco Suárez".Anuario Filosófico, 2017. 50 (2): p. 269-296.

25 Podría argüirse que el contractualismo primario también admite un concepto de ley natural, a saber, el que parta y se desarrolle únicamente a partir del concepto de interés propio. Aunque eso es cierto, no obsta las distinciones que hemos hecho aquí. Sólo desplaza las diferencias al nivel de la ley natural. Tendremos, entonces, teorías de la ley natural basadas únicamente en — dicho en clave escolástica — la consecución de bienes útiles y otras basadas en la consecución de bienes honestos (o útiles y honestos simultáneamente).
} 


\section{La potestad política como propiedad emergente y la peculiaridad del contractualismo suareciano}

LA COMPLEMENTARIEDAD INDICADA ENTRE IUSNATURALISMO Y CONTRACTUALISMo derivado parece difuminar, no sólo la distinción entre ambos sino, además, la distinción entre las teorías políticas tardoescolásticas, como la de Suárez, y las teorías políticas modernas. Sin embargo, lo que demuestra el examen realizado hasta aquí, es que la distinción entre las teorías iusnaturalistas tardoescolásticas y las teorías iusnaturalistas modernas no estriba $-\mathrm{o}$ no necesariamente- en que unas recurran a justificaciones contractualistas (o convencionalistas) y las otras no, o en que aquellas recurran menos a ese tipo de justificaciones que estas. De hecho, puede ser el caso que la situación sea precisamente la inversa. Así, por ejemplo, a diferencia de Suárez, Locke no recurre al contrato para justificar la propiedad. De este modo, mientras la propiedad — según el modo de hablar de los juristas — sería para Locke de derecho natural, para Suárez sería tan solo de derecho humano ${ }^{26}$.

Pero, con independencia de otras diferencias que puedan señalarse entre la teoría política de Suárez y la de sus sucesores, aquí queremos llamar la atención sobre una en particular, referida a su teoría contractualista del poder político. Más precisamente, referida al carácter emergente de la potestad política como resultado de la unión de varios hombres en un cuerpo político.

Los puntos de partida de la teoría de Suárez del poder político son, por una parte, la libertad natural de los hombres y, por otra, el carácter natural de la comunidad política. Suárez recurre además a ese carácter natural para explicar el sentido del dictum paulino de que todo poder viene de Dios, y que servía de punto de partida a la reflexión política salmantina. Dicho, resumidamente, la explicación es como sigue:

1) "La magistratura civil dotada de poder temporal para gobernar a los hombres es justa y muy conforme a la naturaleza humana" ${ }^{27}$.

2) Dicha rectitud y conformidad se puede demostrar, primero, a partir del hecho de que "el hombre es un animal social y de una manera natural y recta tiende a vivir en comunidad" ${ }^{28}$. De todas las comunidades, la más perfecta es la política que, por tanto, es también la más necesaria.

3) En segundo lugar, dicha rectitud se demuestra también a partir del hecho de que "en una comunidad perfecta es necesario un poder a cuyo cargo esté

\footnotetext{
${ }^{26}$ Suárez, F., Las Leyes, op. cit., II, 19, 4.

27 Ibid., III, 1, 1

${ }^{28}$ Ibid., III, 1, 3.
} 
el gobierno de la comunidad" ${ }^{29}$. Esto es necesario porque, por un lado, los intereses de los hombres no siempre son convergentes y, por otro, "a los hombres — conforme a su naturaleza — no los gobiernan políticamente ángeles ni Dios mismo inmediatamente" 30 .

4) Por tanto "el magistrado humano, si es soberano en su esfera, tiene poder para dar leyes en el campo que le corresponde, a saber, leyes civiles o humanas, las cuales en virtud del derecho natural puede dar válida y justamente observando las otras condiciones necesarias para la ley" ${ }^{31}$.

5) El dictum paulino, por su lado, se explica porque Dios es el autor de la naturaleza y, en la medida que para el hombre es natural vivir en una comunidad política, es también autor del poder político. De hecho, dice Suárez enfáticamente que "Dios es el autor no sólo principal sino también exclusivo de este poder" 32 .

6) Dado, por otra parte, que todos los hombres son naturalmente libres, es preciso afirmar que "el supremo poder público, considerado en abstracto [i.e., con independencia de la forma de gobierno], fue conferido directamente por Dios a los hombres unidos en Estado o comunidad política perfecta; y no precisamente en virtud de una institución o acto de otorgamiento especial y como positivo, completamente distinto de la creación de la naturaleza, sino que se sigue necesariamente del primer acto de su fundación" 33 .

En consecuencia, la máxima paulina "el poder viene de Dios" debe entenderse como queriendo decir que Dios otorga el poder al pueblo y que el pueblo — dada la imposibilidad de permanecer en ese estado de "democracia natural" - lo cede a aquel o aquellos que ejercerán la autoridad política. Esa democracia natural es el resultado de la libertad natural de los hombres ${ }^{34}$. El pueblo, por su parte, no debe entenderse como un mero agregado, como una muchedumbre, sino, dice Suárez, como "un cuerpo místico que moralmente puede llamarse uno por su naturaleza"

La conclusión de todo lo anterior (7) es que el poder político "inmediatamente reside en la comunidad; luego para que comience a residir justamente en alguna persona como en soberano, es preciso que se le entregue con consentimiento de la

\footnotetext{
29 Ibid., III, 1, 4.

30 Ibid., III, 1, 5.

31 Ibid., III, 1, 6.

32 Ibid., III, 3, 4.

${ }^{33}$ Suárez, F., Defensio fidei III, Madrid: Consejo Superior de Investigaciones Científicas, 1965, III, $2,5$.

${ }^{34}$ Suárez, F., Defensio Fidei, op. cit., III, 2, 8.

35 Suárez, F., Las Leyes, op. cit., III, 2, 4.
} 
comunidad (ut ex consensu comunitatis illi tribuatur)" ${ }^{36}$. De este modo, aunque el poder político en general viene de Dios, la autoridad de los gobernantes particulares proviene del consentimiento del pueblo.

Prima facie la explicación de Suárez del origen del poder político no parece muy diferente de otras teorías contractualistas. Sin embargo, y a propósito de la potestad legislativa, Suárez sostiene que el poder de dar leyes "por sola la naturaleza de la cosa, no reside en ningún hombre en particular sino en el conjunto de hombres" ${ }^{37}$. $\mathrm{O}$, dicho de otro modo, que "cada uno de los hombres, por naturaleza, posee en parte — por decirlo así - virtud para formar una comunidad perfecta, y cuando la forman, por el mismo hecho aparece (resultat in tota illa hec potestas) en ella este poder" 38 (énfasis añadido).

Una vez que los hombres se congregan en una comunidad política perfecta, el poder político para el gobierno de dicha comunidad surge necesaria e inevitablemente, pues sin él dicha comunidad no podría alcanzar sus fines. No obstante, si se los toma de modo separado, los hombres carecen de ese poder o, al menos, de uno de sus elementos esenciales, como es el poder legislativo. Y carecen de él precisamente en virtud de la libertad natural de que cada uno de ellos goza.

Esta tesis del carácter emergente del poder legislativo no parece repetirse en los contractualistas posteriores, ni entre aquellos que suscriben el contractualismo primario ni, tampoco, entre aquellos que adhieren a alguna forma de contractualismo derivado. Para comprobarlo es preciso repasar la caracterización que ofrece Suárez del poder político cuando intenta demostrar que tal poder no se encuentra en los hombres tomados individualmente. Así tomados, dice, los hombres no tienen autoridad para hacer cosas como infligir castigo a "los malhechores incluso con la pena de muerte", "señalar en una materia el término medio de la virtud necesario para su honestidad", dictar leyes que tengan el efecto de obligar en conciencia o "vengar las injusticias de cada uno" ${ }^{39}$. En consecuencia, esta clase de potestades legislativas "no se da en cada uno de los hombres tomados por separado, ni en el conjunto o multitud de ellos como en confuso y sin orden ni unión de los miembros en un cuerpo". Por el contrario, tales potestades sólo surgen allí donde los hombres se reúnen en ese "cuerpo místico" que es la sociedad política perfecta ${ }^{40}$.

Si se compara esa enumeración con la definición del poder político que ofrece Locke como "el derecho de dictar leyes bajo pena de muerte" u otras menos graves

\footnotetext{
36 Ibid., III, 4, 2.

37 Ibid., III, 2, 3.

38 Ibid., III, 4, 1.

39 Ibid., III, 3, 2.

${ }^{40}$ Ibid., III, 3, 6.
} 
con el fin de preservar la propiedad, defender el Estado y lograr el bien público ${ }^{41}$, resulta claro que, a diferencia de Suárez, Locke cree que los hombres individualmente considerados (es decir, antes de la constitución de una "comunidad perfecta") sí tienen derecho a juzgar y castigar y vengar las injusticias que se cometen, tanto en sus propias personas como en la de otros. Esto es lo que Locke llama el "poder ejecutivo de la ley natural" ${ }^{2} \mathrm{y}$ advierte que se trata de una doctrina que puede resultar extrańa al lector ${ }^{43}$. La introduce porque cree que sin ella no se podría explicar el origen de la potestad para castigar que tienen los magistrados civiles. Los hombres renuncian a este poder "completamente" cuando constituyen una sociedad civil. Entonces lo ponen manos de un poder legislativo ${ }^{44}$.

De modo que en la concepción de Locke - y sin perjuicio de la tarea de determinar las leyes naturales mediante leyes positivas ${ }^{45}$ - el poder político deriva directamente del poder que tienen los individuos de modo natural, cuando se los toma en forma separada. Por esa razón, y parafraseando a Nozick, bien podría decirse que los poderes legítimos de la autoridad política "son meramente la suma de los derechos individuales" que sus ciudadanos le han transferido; que "ningún derecho nuevo ni facultad nueva surge; cada derecho de la asociación se descompone, sin residuo, en aquellos derechos individuales pertenecientes a los distintos individuos que actúan solos en un estado de naturaleza" ${ }^{46}$.

Una concepción análoga parece encontrarse en Hobbes, aunque sostenida sobre bases diferentes. En su caso la potestad del soberano no parece ser cualitativamente diferente de la potestad de los súbditos antes del contrato, sino tan solo cuantitativamente diferente. La razón es que antes del mismo, todos los hombres tienen derecho a todo. La renuncia de ciertos derechos con vistas a la paz y, más precisamente, el derecho a resistir a otros no da a aquellos en favor de quienes se hace la transferencia "ningún derecho nuevo". Esa renuncia, por su parte, da por sí sola origen al "poder supremo, o mando principal, o dominio" ${ }^{47}$. Como Locke, entiende que existe un derecho a castigar en estado de naturaleza. Y aunque sea cierto que el poder del soberano es absoluto, debe entenderse que de ello no se sigue una diferencia cualitativa — como en el caso de Suárez- entre sus potestades y las de sus súbditos, sino tan solo cuantitativa. Se trata, ciertamente, de un poder "mayor

\footnotetext{
${ }^{41}$ Locke, J., Segundo tratado..., op. cit., $\$ 3$.

42 Ibid., $\$ 89$.

43 Ibid., $\$ 9$.

44 Ibid., \$\$130-131.

45 Ibid., $\$ 124$.

${ }^{46}$ Nozick, R., Anarquía, Estado y utopía, Fondo de Cultura Económica, Buenos Aires, 1988, p. 94.

47 Hobbes, T., De Cive. Elementos filosóficos sobre el ciudadano, Madrid, Alianza Editorial, 2000, p. 119
} 
que ningún que pueda ser concedido por los hombres, o que ningún mortal pueda tener sobre sí mismo" ${ }^{48}$, pero no porque sea sustancialmente diferente del poder del soberano, sino tan solo porque ningún hombre individualmente considerado tiene tanto poder como el soberano. Por esta razón, a lo que se renuncia en el contrato es "mi derecho de gobernarme a mí mismo" (my Right of Governing my selfe) ${ }^{49}$.

Otro tanto cabría afirmar de Rousseau, que al momento de explicar el pacto social afirma que los hombres "no pueden engendrar fuerzas nuevas, sino sólo unir y dirigir aquellas que existen" ${ }^{50}$. La comunidad política, por tanto, no es más que una "agregación de fuerzas", que supera la resistencia de las fuerzas particulares. De ahí que, por otra parte, la cláusula a la que se reduce el contrato social es una sola: "la enajenación total de cada asociado con todos sus derechos a toda la comunidad" 51 . Esa enajenación viene exigida por la voluntad general, que no es una potestad ni reside en ningún individuo. Es un principio normativo que condiciona el ejercicio de las fuerzas de los contratantes. Dichas fuerzas, sin embargo, parecen originarse exclusivamente en los ciudadanos particulares.

\section{Conclusiones}

DADA LA EQUiVOCIDAD DEL CONCEPTO DE CONTRACTUALISMO, la disyuntiva entre contractualismo y iusnaturalismo parece ser más bien falsa. También para el caso de Suárez. Esta constatación, por otra parte, no significa negar o desdibujar las diferencias que existen entre el contractualismo suareciano y el de sus sucesores. De hecho, hemos apuntado una cuyo examen puede resultar muy prometedor. Baste la siguiente conjetura a modo de ejemplo (y conclusión): las diferencias que existen acerca de la naturaleza y origen del poder político explican las diferencias acerca de la noción de bien común. El hecho de que Suárez tenga una noción sustantiva y no meramente agregativa de bien común (como parece ocurrir en el caso de Hobbes o Locke), puede explicarse por su teoría del origen de la potestad civil. Después de todo, si esa potestad es un poder emergente, no reconducible a los poderes de los individuos separados en estado de naturaleza, entonces sí sería posible (o al menos más plausible) sugerir que el bien común, como fin de la potestad legislativa, no se identifica con el bien particular de los miembros de la sociedad. El examen de la verosimilitud de esta conjetura deberá quedar, sin embargo, para otra ocasión.

\footnotetext{
${ }^{48}$ Hobbes, T., op. cit., p. 129.

49 Hobbes, T., Leviatán, ob. cit., p. 141

50 Rousseau, J.-J., Del contrato social..., op. cit., p. 38.

51 Ibid., p. 39.
} 


\section{Referencias Bibliográficas}

Buchanan, J. M. (2009). Los límites de la libertad. Entre la anarquía y el Leviatán (V. Sardón, Trans.). Madrid: Katz Editores.

Dworkin, R. (1984). Los derechos en serio (M. Guastavino, Trans.). Barcelona: Editorial Ariel.

Hernández-Fradejas, F. (2017). Derecho de propiedad privada y fiscalidad en Francisco Suárez. Anuario Filosófico, 50 (2), 269-296.

Hobbes, T. (1992). Leviatán o la materia, forma y poder de una República eclesiástica y civil (M. Sánchez Sarto, Trans.). Buenos Aires: Fondo de Cultura Económica.

Hobbes, T. (2000). De Cive. Elementos filosóficos sobre el ciudadano (C. Mellizo, Trans.). Madrid: Alianza Editorial.

Kant, I. (1900). Gesammelte Schriften (Akademie-Ausgabe). Walter de Gruyter, Berlin.

Letelier Widow, G. (2018). La noción de "estado de naturaleza" en el pensamiento político español del siglo XVI. Ideas y valores, 67 (167), 199-222. doi:http://dx.doi.org/10.15446/ideasyvalores.v67n167.56033

Locke, J. (2000). Segundo tratado sobre el gobierno civil: un ensayo acerca del verdadero origen, alcance y fin del gobierno civil (C. Mellizo, Trans.): Alianza Editorial.

Nozick, R. (1988). Anarquía, Estado y utopía (R. Tamayo, Trans.): Fondo de Cultura Económica, Buenos Aires.

Rawls, J. (2002). La justicia como equidad. Una reformulación (E. Kelly Ed.). Barcelona: Paidós.

Rousseau, J.-J. (1998). Del contrato social. Discursos (M. Armiño, Trans.). Madrid: Alianza Editorial.

Schwartz Porzecanski, D. (2005). Francisco Suárez y la tradición del contrato social. Contrastes: revista internacional de filosofia (10), 119-138.

Suárez, F. (1965). Defensio fidei III. Madrid: Consejo Superior de Investigaciones Científicas.

Suárez, F. (1967). Las Leyes (J. R. E. Muniozguren, Trans.). Madrid Instituto de Estudios Políticos. 
Tellkamp, J. A. (2014). Francisco de Vitoria and Luis de Molina on the Origin of Political Power. In A. Santiago Culleton \& R. Hofmeister Pich (Eds.), Right and Nature in the First and Second Scholasticism. Derecho y Naturaleza en la primera y segunda escolástica (pp. 231-247). Bélgica: Brepols.

DOI: https://doi.org/10.15366/bp2021.26.008

Bajo Palabra. II Época. No26. Pgs: 161-178 